\title{
Psycholinguistic Analysis of Cognitive-Discursive Practices of Mediatext Addressee: Interdisciplinary Study
}

\author{
Elina V. Bulatova \\ Department of Russian \\ Language and Stylistics \\ Ural Federal University \\ Ekaterinburg, Russia \\ elina2824@yandex.ru
}

\author{
Anna S. Alekseeva \\ Department of Clinical Psychology and Psychophysiology \\ Ural Federal University \\ Ekaterinburg, Russia \\ Nurochka_k@mail.ru
}

\author{
Olga V. Lomtatidze \\ Department of Biology and Fundamental Medicine \\ Ural Federal University \\ Ekaterinburg, Russia \\ Olya.1@mail.ru
}

\begin{abstract}
Media space is continually expanding: more and more areas of people's daily activities are connected with the media spheres. The nature of the impact of media messages on humans requires comprehensive study. This article presents the results of the complex psycholinguistic analysis of cognitivediscursive practices of the author and the addressee of the text, during which the peculiarities of the sense structure and expressive plan of publication were determined, experimental research of visual perception of the text was carried out with the help of eye-tracking as well as the readers questionnaire. The synthesis of the obtained data made it possible to determine the impact of the publication, the accounting of which is necessary to make recommendations to the participants of the media communication process.
\end{abstract}

Keywords - cognitive-discursive practice, media text, eyetracking, visual perception, visual fixation, saccades

\section{INTRODUCTION}

Cognitive-discursive practice (CD practice) is oral/text activity, understood as an act of knowledge transmission and acquisition. In the aspect of discursive activity of mass media CD-practice is organization of structures of knowledge in media text by the author and their identification and interpretation by the addressee. The interdisciplinary approach makes it possible to describe $C D$ practices from the perspective of different scientific approaches. Linguostilistic, sociological, psycholinguistic methods are of great importance in assessing the activities of media communicants. Comprehensive analysis allows us to study practices of text construction and textual perception in their interaction, to assess the effect of publication influence.

\section{METHODS}

At the first stage of interdisciplinary study of cognitivediscursive practices of media communicants, linguostilistic analysis of meaning structure and expressiveness of publication is carried out, as well as frame analysis, which allows to describe cognitive-discursive practices of the addressee - practice of publication construction. At the second stage, hardware research is carried out, as well as a survey of respondents, which allows to assess cognitive-discursive practices of the addressee - practices of perception of publication.

The questionnaire method allows one to identify the degree of understanding of the main thought of the text, to determine the most significant elements of the message for respondents, to find out the nature of the emotional response of readers and the reasons for its occurrence. The questionnaire includes direct, open questions about opinions: 1) Define the basic idea of publication. 2) Highlight several key, most significant elements of the publication (verbal and (or) visual), which, in your opinion, carry the main semantic load. Please explain your choice. 3) Did you experience emotions while getting acquainted with the publication? If so, which ones? (If the publication did not cause emotion, mark it and skip question 4). 4) What elements of publication (verbal and/or visual) caused emotions? Why? 5) Define the type of text: a) journalism, b) advertising, c) PR.

One of the modern hardware methods of perception studying is the eye-tracking. Analysis of eye movements provides an opportunity to objectively investigate a human mental states [1]. Through the perception of visual images, oculomotor activity is associated with other psychophysiological functions. The patterns of eye movement reflects the dynamics of cognitive processes: attention, thinking, and their focus - interest, attitude to the stimulus [2]. 
Eye-tracking as one of the methods of oculography in addition to its instrumental and measuring function also includes information-communicative and interpretive parts, allowing not only to record the fact of perception of the text, but also to evaluate its cognitive components [3].

\section{RESULTS}

\section{A. Analysis of Text Meaning Structure and Expressiveness}

Let's present the results of the complex analysis of CDpractices of perception of the media text "Our Miska at the marathon Europe-Asia 2018!" [4] is dedicated to the participation of the representative of eco-products company «Medved» (Bear) in the marathon. The survey was attended by 30 students of the Faculty of Journalism of 19 to 25 years old.

The correlation of the data of the analysis of the meaning structure and expressiveness of the text [5] with the results of the survey showed that the techniques used by the author had a cognitive and emotional effect on a small part of the respondents of the sample. Thus, the diad nature of the sense structure, manifested in the presence of explicit (related to the information reason) and implicit (related to the goals of promotion of the company "Bear") basic ideas and conclusions, was "caught" $16.6 \%$ of respondents. The role of expressive beginning modeling the effect of tension, responsible for maintaining interest in the text, was noted by only $6.6 \%$ of respondents. At the same time, $50 \%$ of respondents drew attention to the compositional reception of repetition (calls to "observe a healthy lifestyle"), simulating the effect of convergence, which is responsible for "infecting" readers with emotions. The expressive ending of the text, containing a significant number of exclamation sentences, attracted the attention of $40 \%$ of respondents, with $30 \%$ of readers treating it negatively. The informal style ("Our Miska," etc.) was positively appreciated by $10 \%$ of respondents. The visual component of the publication was considered $53.3 \%$ important element for respondents $13.3 \%$ but experts pointed to the poor quality of the photo, which reduces the impression of getting acquainted with the media message. The text caused positive emotions in only $13.3 \%$ of respondents. $80 \%$ of readers noted that the publication does not belong to journalistic discourse: $23.4 \%$ considered the material advertising, $56.6 \%$ classified it as PR.

It is important to note that in the answers of 11 people (36.6\% of respondents) there are errors: a) called "Bear" symbol of marathon "- 6 people $(20 \%)$," symbol of sports in Russia "- 1 person (3.3\%), "sponsor of race" - 1 person $(3.3 \%)$; B) considered that the marathon had not yet taken place (used verbs of future time) - 6 people $(20 \%)$; C) named the marathon the name of the company "Bear" - 1 person
$(3.3 \%)$. (Several responses contain several errors at the same time).

Not all of these errors indicate read errors. The perception of the note as an announcement is facilitated by the fact that the author uses verbs of different time forms when describing the event. It is reported that "Bear" could not miss the marathon (there is a verb of the past time), took part in it (confirmation of the event is a photo and video of the race). At the same time the author further resorts to the form of the future time: Marathon Europe-Asia is interesting as the strongest athletes will take part in it.

Attributing a "symbolic" function to Bear and designating a marathon by the name of Bear can serve as signals of a weak cognitive trail of publication.

In some cases, in response to the question of the questionnaire, respondents gave an assessment of the publication as a whole: (a) "the title, photos, name of the organization and contacts, color gamut and errors distract from the main text. It was difficult to concentrate. The structure of the publication is unarmonic, it is difficult to understand what this text is about"; B) "exclamation marks, pictures of poor quality, color and font - it is unpleasant to look at such publication"; C) "photography, the phrase" our bear, the headline - all this showed that the race was actually and the author of the publication is proud that Bear took part in it. The spelling error forced a little thinking about what a competent and mature journalist writes. Moreover, the constant mention of the health life style reinforced these doubts.

Correlation of analysis findings of semantic structure and the emotional and estimated party of the text with results of poll showed that the receptions used by the author made cognitive and emotsiogenny impact on an insignificant part of respondents of this selection: caused emotions, drew attention to a text element and promoted his storing

\section{B. Analysis of Eye-Tracking Data}

Let's turn to the eye-tracking data. Visual perception involves the fixation of a eye on an object, word, or sentence, during which objects are recognized and analyzed [6]. The duration of fixation thus reflects the visual information processing time. The number of fixations can be related to both the features of the stimulus: semantic significance, localization, complexity, and the features of the observer, his experience and skills [7].

In the course of the work, an analysis of the eye fixation of the subjects on the selected interest zones, which include the title (text1), main text (text2), contacts (contakt), text (logo_text) and graphic logos (logo_bear), photograph: bear figure (bear_fig) and athletes (Fig. 1), was carried out. 


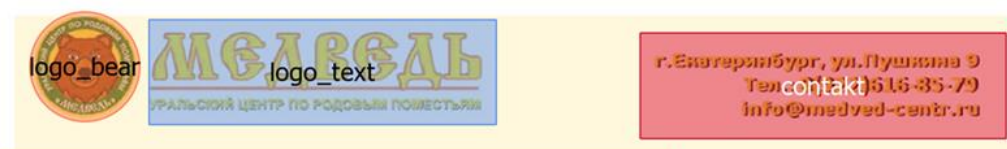

Наш Мишка на Марафоне Европа-Азия 2018! 8 октября 2018 - $\underline{\text { Sunnytly }}$

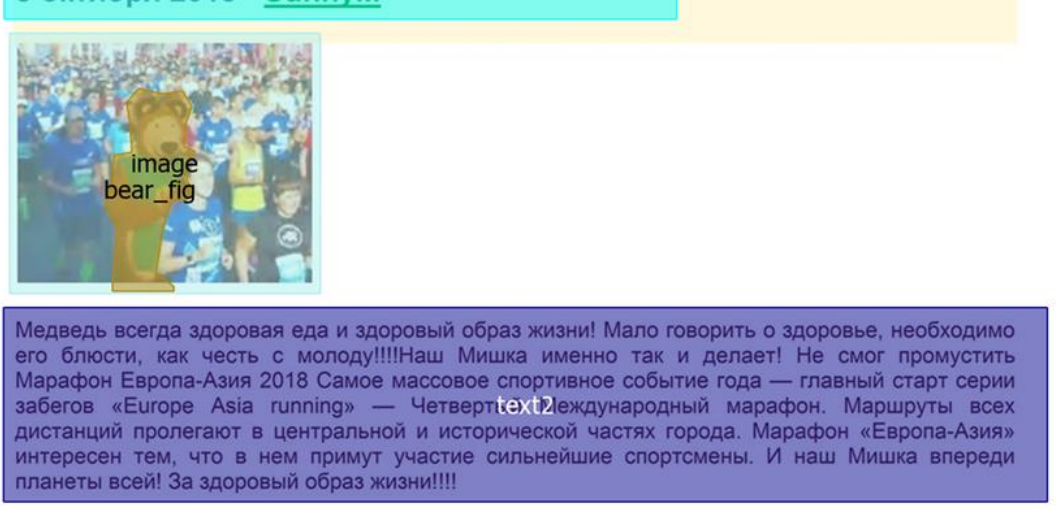

Fig.1 Media Text with Selected Interest Areas

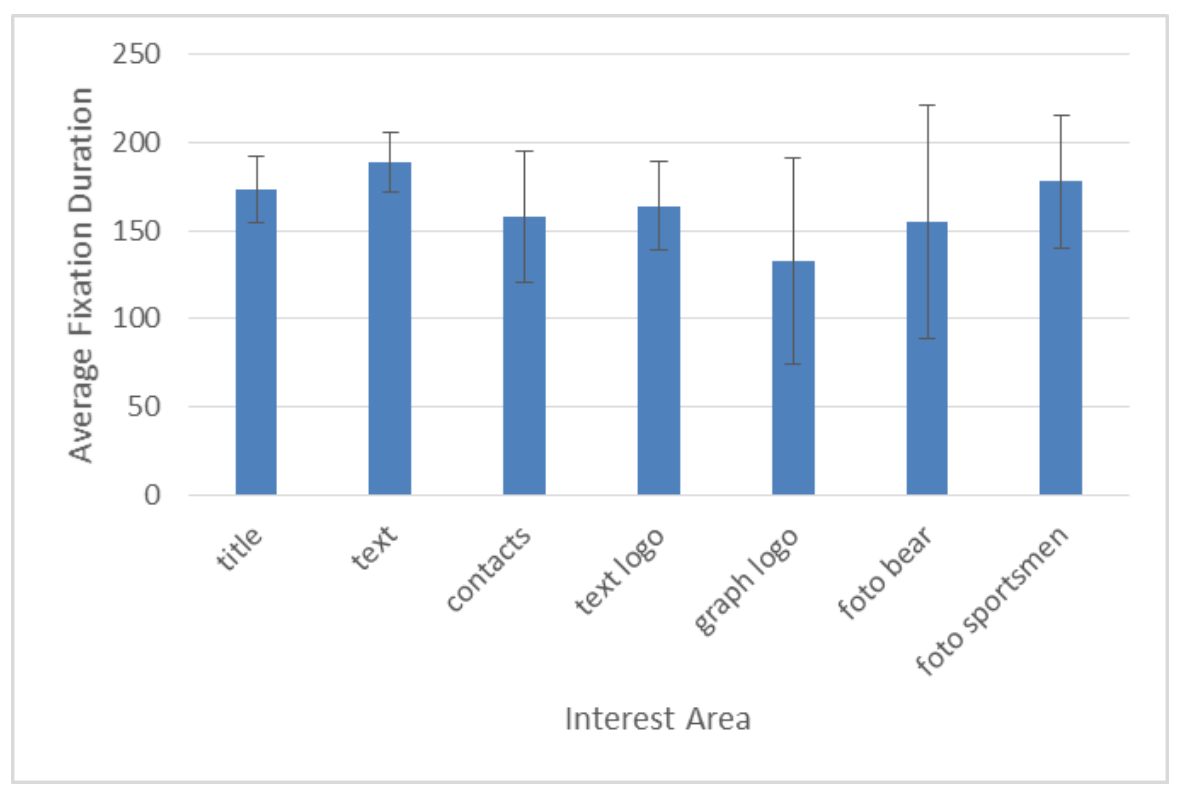

Fig.2 Distribution of the Average Fixation Duration on the Selected Interest Areas 


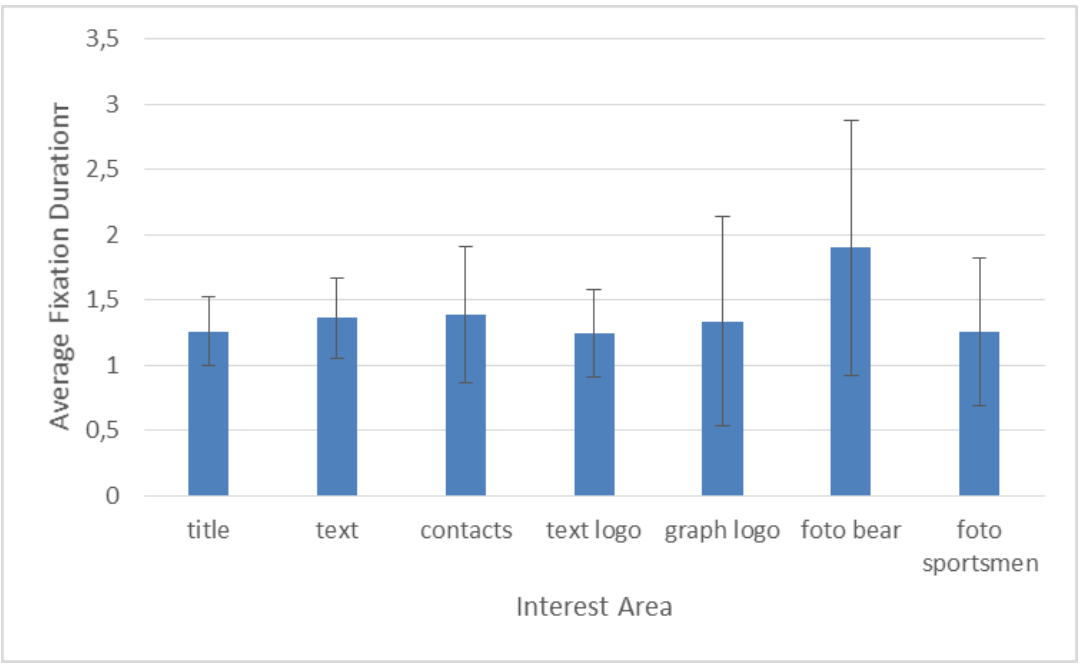

Fig.3 Distribution of the Relative Number of Fixation per Area Element

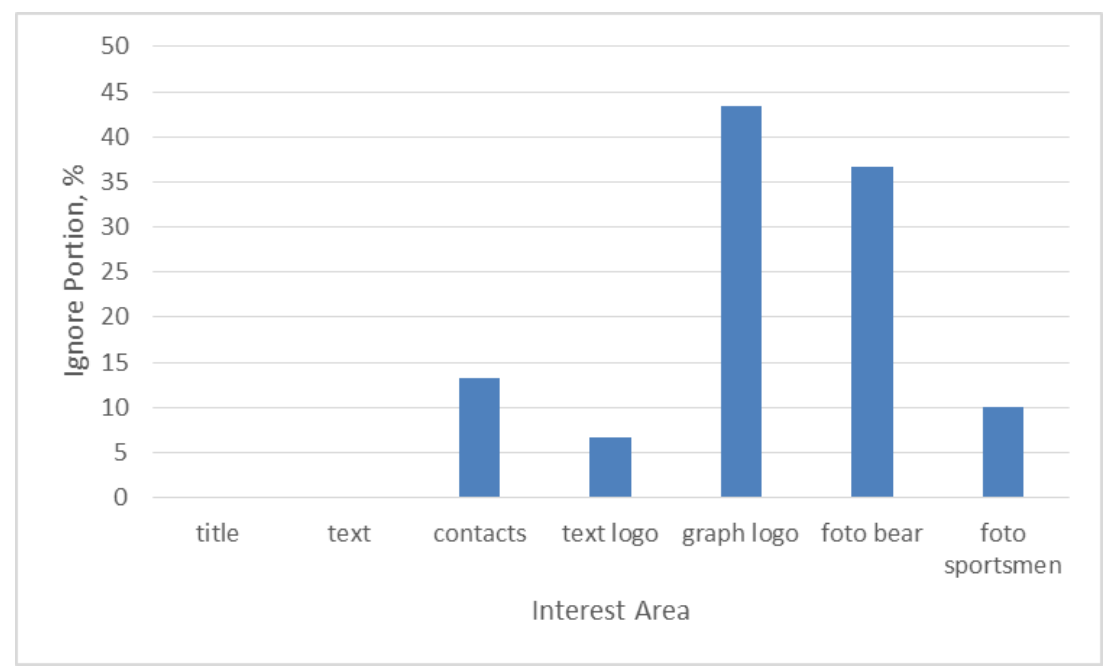

Fig.4 Percentage of the Selected Interest Zone Ignored

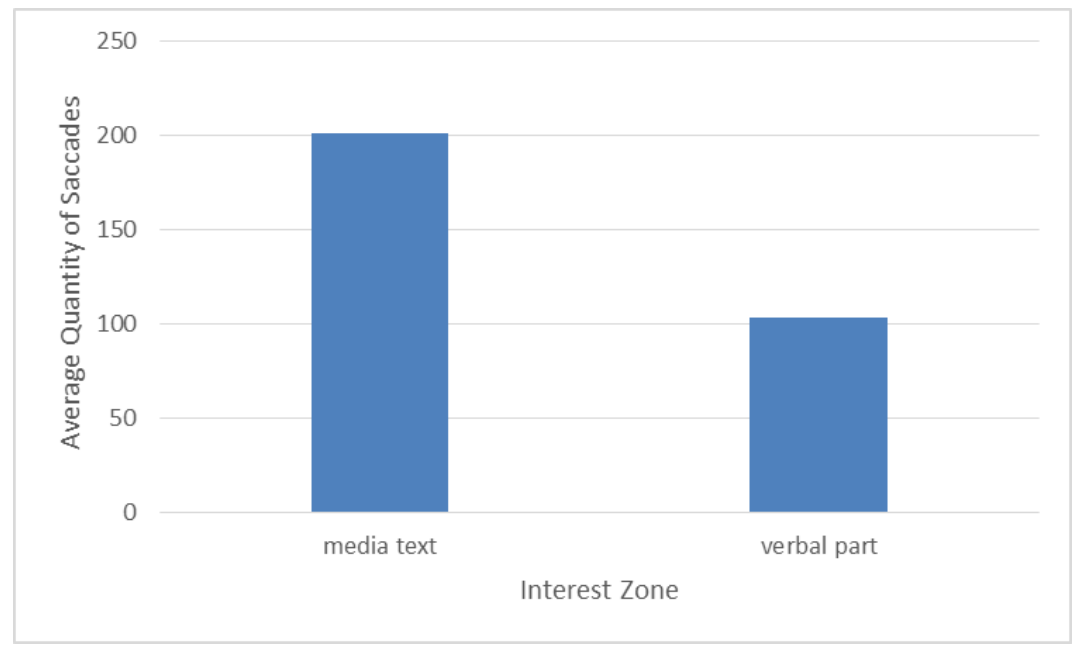

Fig.5 Average Number of Saccades per Allocated Stimulus 
Analysis of the average fixation duration (Fig.2) revealed significant differences $(\mathrm{F}=4.54, \mathrm{p}<0.05)$ between the perception of the visual logo and the main text, which is a consequence of different information saturation and difficulty of recognition of these zones, leading to changes in the time costs during perception [8].

Analysis of the relative number of fixations (Fig. 3) of the view per the element of the selected area on average shows that the subjects reliably $(\mathrm{F}=4.45, \mathrm{p}<0.05)$ pay attention to the bear figure in the photograph rather than to the individual words of the main text and the title, which indicates the importance of the visual image in attracting the interest of the respondent. In this case, it is necessary that the visual image correspond as much as possible to the text incentives, which will allow one to allocate attention resources optimally. In addition, subjects are more likely to be fixed $(\mathrm{F}=4.34, \mathrm{p}<$ 0.05) on the central part of the photograph (bear) than on the athletes around it, which is proof of the applicability of the law of figure and background in the perception of media text [9].

The study shows that the selected areas of interest could not only attract attention, but also be ignored by the subjects (Fig. 4).

The most common $\left(\varphi^{*}=2,12 \div 5,32, \mathrm{p}<0.05\right)$ are ignored; the graphic logo and bear figure are the most rare; $\left(\varphi^{*}=2,49 \div 5,32, \mathrm{p}<0.05\right)$ ignored the title and body text. That is, all subjects pay attention to text and title, the most of them also view contacts, text logo and photos of athletes, but bear figure and logo can be ignored by respondents more often than other zones. Note that some of the subjects completely ignored the photo and logo. The other part, which drew attention to them, most often recorded the view on the image of the bear. So visual perception of simple graphic images can thus either follow the path of holistic perception of an image with multiple but short-term fixations, or be completely excluded from it, due to the inclusion of an individual attention selectivity mechanism.

Saccadic eye movements are the rapid movement of the eye from one point of fixation to another when random looking at an object. The amplitude of saccades, i.e. the distance that the look passes from one fixation to another, depends on the complexity and type of stimulus, the characteristics of the nervous system, and the experience of the recipient. The number of saccades can be related to the applied strategy of perception, the task set, the features of the stimulus $[10,11]$.

According to the results of the work, about half of saccades are in the verbal part of media text (Fig.5).
However, when considering the relative number of saccades per element of the extracted stimulus (Fig.6), it can be seen that the relative number of saccades per word in the verbal part of the media text is lower than the relative number of saccades per element of the media text as a whole. This relationship may be due to the presence in the media of elements whose visual perception requires more visual movements than to read and identify individual words in the verbal part [12]. Such stimuli, for example, may be a logo or a bear figure in the center of the photograph.

The average amplitude of saccade in the verbal part of media text is lower than in the stimulus as a whole, which characterizes the greater complexity for perception of the verbal fragment in relation to the media text as a whole (Fig.7).

Thus, analysis of saccadic movements shows that in the perception of verbal passage and media text in general, subjects use different strategies: aiming, few short saccades to read the verbal part and blurred, numerous long saccades to view the entire media text.

Eye-tracking technologies allow us to complete the understanding of the specifics of the cognitive-discursive practices of the addressee [13, 14]. Thus, it has been established that in the perception of media text, the main attention of readers (see red, yellow and green zones in Fig. 8) is attracted by the verbal component of the publication. At the same time, deviations from the norm, deliberate (expressive techniques) and unintentional (typos, errors), are areas of maximum attention. In our case, such a zone was the typo "Promustit" instead "Propustit" ("miss"), the cognitive processing of which required a lot of time for perception by respondents. At the same time, the noted "zone of interest" was characterized negatively by readers: $46.6 \%$ mentioned the errors of the text during the questionnaire.

The correlation of eye-tracking data with the survey results also demonstrated the importance of the visual component for the addressee: $53.3 \%$ of respondents described the photo as the most important element of the publication. The addressee must take into account this circumstance and takes care of the clarity and attractiveness of the visual image, as it is on the basis of the primary perception of the photo (or other image) that the hypothesis about the content of the publication is formed and the interest of the respondent is formed. [Rayner, K., Smith, T. J., Malcolm, G. L., \& Henderson, J. M. (2009). Eye movements and visual encoding during scene perception. Psychological Science, 20, 6-10]. 


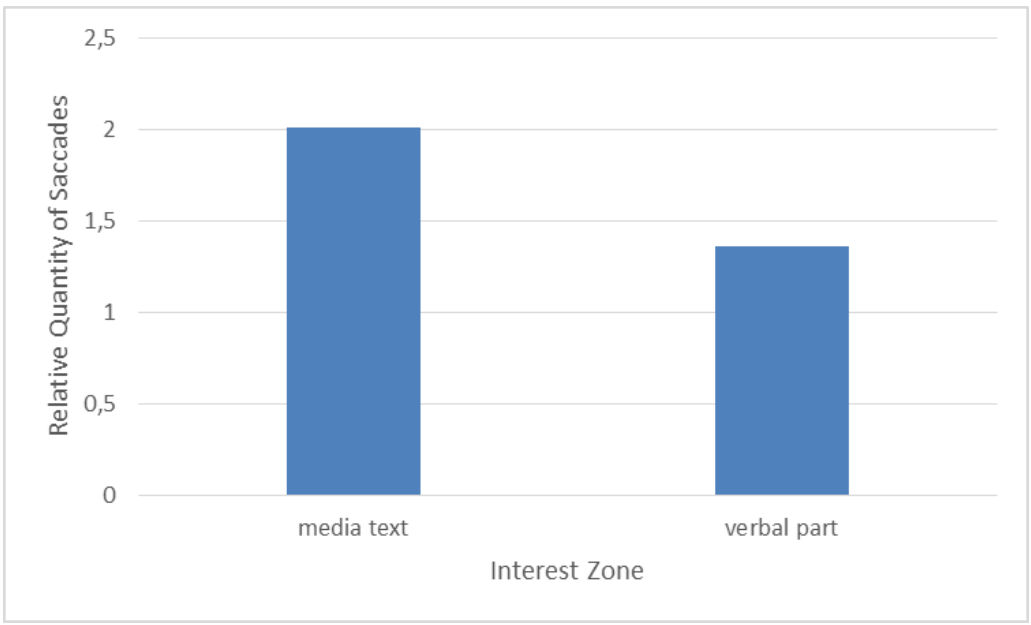

Fig.6 Relative Number of Saccades per Allocated Stimulus

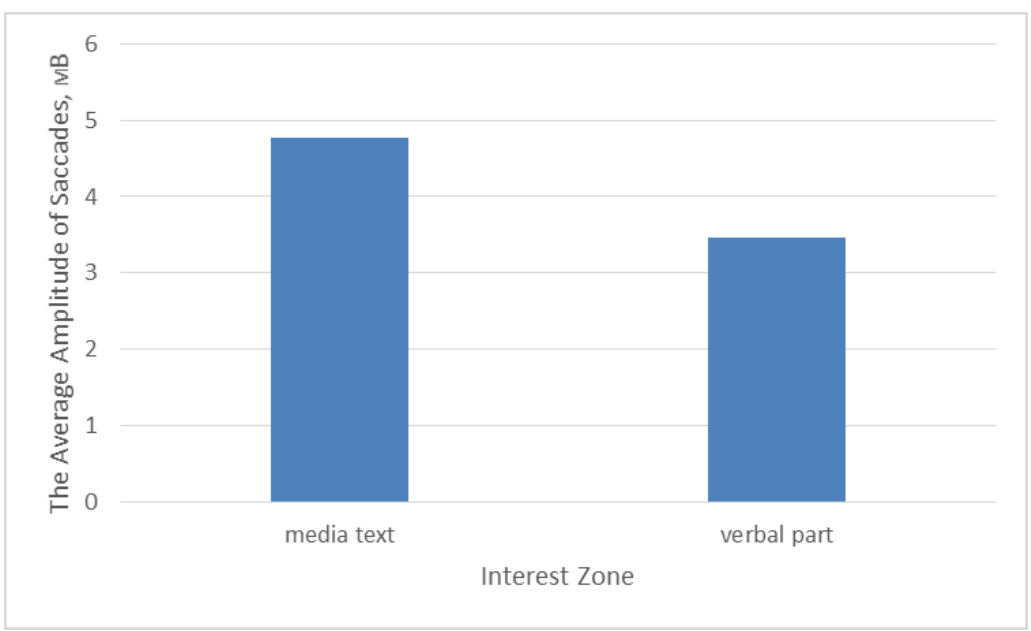

Fig.7 Average Saccade Amplitude by the allocated stimulus

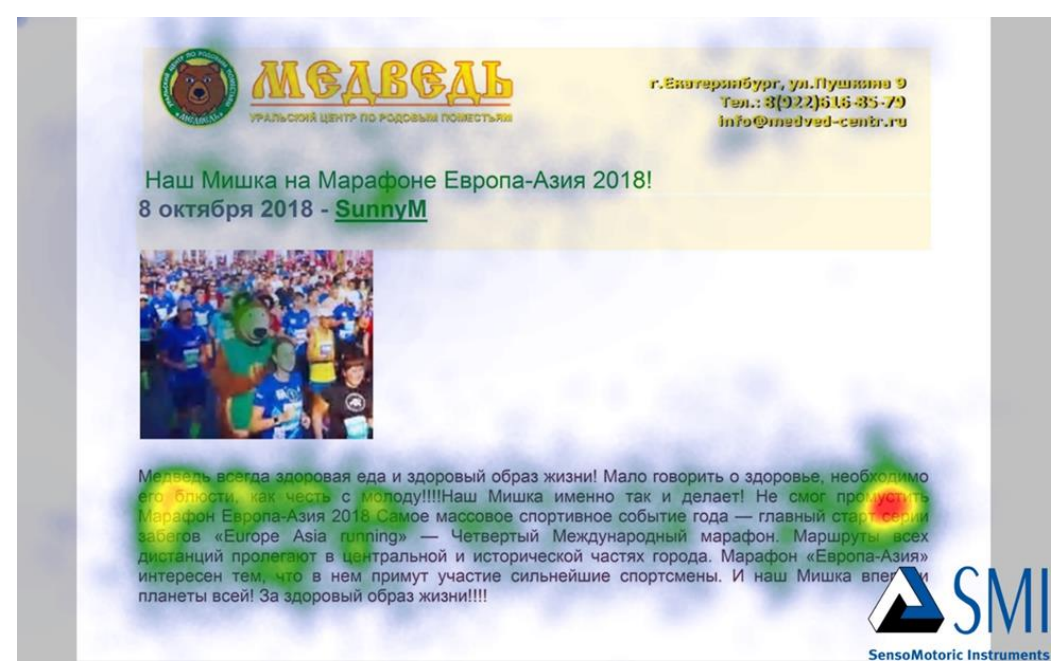

Fig.8 A Heat Eye-Tracking Map 


\section{CONCLUSION}

The features of perception revealed during the complex research can serve as the indicator of the weak cognitive and emotional trace of the used publication caused by a complex of the reasons: existence of mistakes in the text: abundance of exclamations, the small size and illegibility of the photo (therefore a part of respondents ignored it), PR-orientation of material, obvious to readers [15]. The aspiration to draw attention of the potential consumer to activity and products of the Medved company turned back, according to respondents, "excessive emotionality", "an excessive expression", "clamorousness" and led to rejection of the reader.

The study of cognitive-discursive practices of media communicants within the framework of the interdisciplinary approach allows one to establish causal connections between the stimulus - media message - and the response of the addressee to it and to make conclusions about the affecting effect of media texts, on the basis of which recommendations can be formulated to the compilers of media messages.

\section{References}

[1] D. Dario, Salvucci and H. J. Goldberg, "Identifying fixations and saccades in eye-tracking protocols. In Proceedings of the symposium on Eye tracking research \& applications," ETRA '00. ACM Press, Pp. 71$78,2000$.

[2] T. McCoy-Thomas, "Eye Tracking and Learning Predictability," Journal of International Education and Practice, V. 02, Issue 04, p. 11-18, December 2019.

[3] J.Škrabánková, E. Trnová, "Researching Students Gifted in Science Using the Method of Eye Tracking," e-Pedagogium, 15(4), pp. 79-93, 2015.

[4] Sunny M. URL:http://www.medved-centr.ru
[5] E.V. Bulatova, "Kognitivno-diskursivnye praktiki adresanta kommercheskih PR-tekstov Ad quaestu," Kognitivnye issledovanija jazyka. Vypusk HHHVIII - M. : In-t jazykoznanija RAN ; Tambov : Izdatel'skij dom TGU im. G. R. Derzhavina, pp. 520-526, 2019

[6] D. J. Schad, S. Risse, T. Slattery \& K. Rayner, "Word frequency in fast priming: Evidence for immediate cognitive control of eye movements during reading,"Visual Cognition, 22, pp. 390-414, 2014.

[7] K. Rayner, "Chase slattery eye movements as reflections of comprehension processes in reading," Scientific Studies of Reading, V. 10, № 3, P. 241-255, 2006.

[8] D. Parkhurst, K. Law, E. Niebur, "Modeling the role of salience in the allocation of overt visual attention," Vision Research, 42, pp. 107-123, 2002.

[9] S. Saida, M. Ikeda, "Useful field size for pattern perception," Perception \& Psychophysics, 25, pp. 119-125, 1979.

[10] D. Garreta, "Understanding eye movements: psychophysics and a model of primary visual cortex," A dissertation at Universitat Autònoma de Barcelona to fulfil the degree of Doctor of Philosophy, July 26, 2019. $207 \mathrm{p}$.

[11] C. Pierrot-Deseilligny, R.M. Müri, C.J. Ploner, B. Gaymard, and S. Rivaud-Péchoux, "Cortical control of ocular saccades in humans: a model for motricity," In Progress in Brain Research, Elsevier, pp. 3-17, 2003.

[12] R. Radach, A. Kennedy, K. Rayner, "Eye Movements and Information Processing During Reading," Hove: Taylor \& Francis [CAM], 2004, 407 p.

[13] R. Kliegl, E. Grabner, M. Rolfs et al., "Length, frequency, and predictability effects of words on eye movements in reading," European Journal of Cognitive Psychology, V. 16, № 1-2, pp.262- 284, 2004.

[14] N. Landwehr, S. Arzt, T. Scheffer, R. Kliegl, "A Model of Individual Differences in Gaze Control During Reading," Proceedings of the Conference on EMNLP, pp. 1810-1815, 2014

[15] K. Rayner, T. J. Smith, G. L. Malcolm,., \& J. M. Henderson, "Eye movements and visual encoding during scene perception," Psychological Science, 20, pp. 6-10, 2009. 